\title{
Characterization of Bacillus thuringiensis isolated from infections in burn wounds
}

\author{
Per H. Damgaard ${ }^{a}$, , Per E. Granum ${ }^{b}$, José Bresciani ${ }^{a}$, Maria V. Torregrossa ${ }^{\mathrm{c}}$, \\ Jørgen Eilenberg ${ }^{a}$, Laura Valentino ${ }^{c}$ \\ a Department of Ecology and Molecular Biology, The Royal Veterinary and Agricultural University, Thorvaldsensvej 40, \\ DK-1870 Frederiksberg C, Denmark \\ ${ }^{\mathrm{b}}$ Department of Pharmacology, Microbiology and Food Hygiene, Norwegian College of Veterinary Medicine, P.O. Box 8146, \\ $\mathrm{N}-0033$ Oslo, Norway \\ c Department of Hygiene and Microbiology, University of Palermo, via del Vespro 133, 90127 Palermo, Italy
}

Received 19 December 1996; revised 20 February 1997; accepted 20 February 1997

\begin{abstract}
Four strains of Bacillus thuringiensis were isolated from infections in burn wounds and from water used in the treatment of burn wounds. The strains produced large parasporal inclusion bodies composed of 141, 83, and $81 \mathrm{kDa}$ protoxins. The four strains were tested for insecticidal activity against larvae of Pieris brassicae and Aedes aegypti but showed no activity; Vero cell assays for the production of enterotoxins were also negative. Attempts to classify the strains according to flagellar H-serotype showed them all to be non-flagellated. Apart from two occupational health accidents that occurred during the handling of highly concentrated B. thuringiensis fluids, this is the first report of B. thuringiensis causing non-gastrointestinal clinical infection in immunosuppressed patients.
\end{abstract}

Keywords: Bacillus thuringiensis; Bacillus cereus; Burn wound

\section{Introduction}

Bacillus cereus is a well-known agent of food poisoning; however, non-gastrointestinal B. cereus infections of humans and domestic animals have traditionally received greater recognition. An increasing number of clinical infections from burn wounds [1], insect bites [2,3], meningitis [4], and endophthalmitis [5] have been reported. Previously, hospital microbi-

\footnotetext{
* Corresponding author. Tel: +4535282660 ; Fax: +4535282670
}

ologists would often dismiss $B$. cereus as unimportant although the infections are prevalent [6].

Bacillus thuringiensis, a close taxonomic relative of B. cereus, is used extensively for insect pest control in agriculture, forestry, and vector control, because of increasing environmental concerns about traditional chemical pesticides [7]. B. thuringiensis and B. cereus can only be differentiated by the production of the plasmid-encoded $\delta$-endotoxin by the latter [8]; as this characteristic is unstable and plasmid-borne, many consider B. thuringiensis to be a variant of $B$. cereus [9-11].

Although B. thuringiensis has been used for 50 
years for insect pest control, only two clinical infections caused by this organism have been reported in the literature $[12,13]$. This could be due to the absence of $B$. thuringiensis infections in humans; however, this is unlikely because of the very similar ecology and close taxonomic relationship between $B$. thuringiensis and $B$. cereus. Infections caused by $B$. thuringiensis could therefore potentially be 'hidden' in cases described as B. cereus.

To investigate this possibility, strains originally isolated as $B$. cereus from human infections were re-examined for the presence of $\delta$-endotoxins. Valentino and Torregrossa [14] isolated strains of B. cereus from infections of burn wounds and from water used in the treatment of the burn wounds in an Italian hospital; these strains were later found to produce $\delta$ endotoxin and are consequently B. thuringiensis [8]. The strains are characterized here with identification methods for both B. thuringiensis (e.g., insect bioassays, H-serotyping, and fine structure of $\delta$-endotoxin) and B. cereus (e.g., Vero cell assay).

\section{Materials and methods}

\subsection{Isolation of B. cereus/B. thuringiensis}

In the Burns Centre of Palermo, Italy, B. cereus was isolated from two patients with deep burns (30$70 \%$ body surface area) with surface swabs; the samples were taken from burns and immediately adjacent areas as described in Valentino and Torregrossa [14]. B. cereus was also isolated from two water samples used in the treatment of burn wounds. Strains were examined by a phase-contrast microscope and found to produce parasporal inclusion bodies in the sporangium and were consequently classified as $B$. thuringiensis, according to Bergey's Manual of Systematic Bacteriology [8].

\subsection{Cultures}

The strains used as positive control strains in TEM and the bioassays included $B$. thuringiensis serovar kurstaki (HD-1), serovar israelensis (HD-567) and serovar morrisoni (NB 125) obtained from the International Entomopathogenic Bacillus Centre, Pasteur Institute, Paris, France. All strains have been used commercially for insect pest control.

\subsection{TEM of B. thuringiensis}

B. thuringiensis TBt-81 and TBt-82 isolated from skin lesion and water samples respectively (Table 1) and B. thuringiensis HD-1, HD-567 and NB-125 were grown in T3-sporulation medium [15] for 2 days at $30^{\circ} \mathrm{C}$. The cultures were centrifuged (15 $\min , 10,000 \times g, 5^{\circ} \mathrm{C}$ ) and the pellets were embedded in $4 \%$ Bacto-agar (Difco, USA) and fixed in $2.5 \%$ glutaraldehyde in $0.1 \mathrm{M}$ cacodylate buffer $(\mathrm{pH} 7.1-$ 7.3) over night at $4^{\circ} \mathrm{C}$. After several washes in $0.1 \mathrm{M}$ cacodylate buffer, the pellet were post-fixed in $1 \%$ $\mathrm{OsO}_{4}$ and stained in $0.5 \%$ uranyl acetate and dehydrated via an ethanol series with propylenoxide as an intermediate medium. Pellets were then embedded in Epon (Merck, Germany), and hardened at $60^{\circ} \mathrm{C}$ for two days. Ultrathin sections were cut on a Reichert Ultracut E, stained with $0.2 \%$ uranyl acetate and Reynolds lead citrate, viewed, and photographed in a Phillips CM100 electron microscope at $60 \mathrm{kV}$.

\subsection{H-serotyping}

Reference $\mathrm{H}$ antisera of the 58 currently recognised $B$. thuringiensis serovars were obtained from the Pasteur Institute, France. Agglutination tests among the 58 different antisera and flagella produced by $B$. thuringiensis were done by the method described by de Barjac [16]. In brief, early exponentially growing cultures were inoculated at the agar surface of the inner small tube of a Craigie tube filled with soft nutrient agar $(0.2 \%)$. If motile, the bacteria migrated down the inner tube and up the outer container tube in $24 \mathrm{~h}$. From this, a stock suspension of very motile cells, are tested for agglutination with a range of antisera in small Kahn tubes. A positive reaction is shown by clear contents of a tube and a floccular sediment at the bottom.

\subsection{Insect toxicity tests}

B. thuringiensis strains were examined for their per os insecticidal activities against larvae (neonates) of Pieris brassicae (Lepidoptera; large white butterfly), and mosquito larvae of Aedes aegypti (Diptera). Bac- 
Table 1

Qualitative insecticidal activity against larvae of Pieris brassicae (Lepidoptera)/Aedes aegypti (Diptera), flagella (H) serotype and cytotoxic effects on Vero cells, using Bacillus thuringiensis isolated from skin lesions and water samples in a hospital burn unit

\begin{tabular}{|c|c|c|c|c|c|c|}
\hline \multirow[t]{3}{*}{ Strain } & \multirow[t]{3}{*}{ Source } & \multirow[t]{3}{*}{ H-serotype } & \multicolumn{3}{|l|}{$\%$ Mortality $^{a}$} & \multirow{3}{*}{$\begin{array}{l}\% \text { Inhibition of } \\
\text { protein synthesis in } \\
\text { Vero cells }^{b}\end{array}$} \\
\hline & & & \multirow[t]{2}{*}{ P. brassicae } & \multicolumn{2}{|c|}{ A. aegypti } & \\
\hline & & & & $2 \mathrm{~h}$ & $48 \mathrm{~h}$ & \\
\hline TBt-81 & skin lesion & $\mathrm{NF}^{c}$ & 0 & 0 & 0 & 0 \\
\hline TBt-85 & skin lesion & NF & 0 & 0 & 0 & 0 \\
\hline TBt-82 & water sample & NF & 0 & 0 & 0 & 0 \\
\hline HD-567 & Institute Pasteur & israelensis & 0 & 100 & 100 & $\mathrm{nt}$ \\
\hline
\end{tabular}

${ }^{a}$ Percentage corrected mortality.

${ }^{b}$ Percentage of control.

${ }^{c} \mathrm{NF}=$ not flagellated.

${ }^{d}$ Not tested.

teria were propagated in $\mathrm{T} 3$-sporulation medium which was incubated for 5 days at $30^{\circ} \mathrm{C}$ on a rotary shaker and used directly as test suspension.

Tests for insecticidal activity against $P$. brassicae larvae were performed as previously described using an agar-based artificial diet [17]. The bacterial suspension were mixed into molten diet at a rate of 60 $\mu \mathrm{g} \mathrm{g}^{-1}$ and allowed to set and surface dry, after which 25 neonatal larvae were added. The bioassay preparations were incubated at $20^{\circ} \mathrm{C}$ and the number of live larvae was counted after 5 days.

For the mosquito assays, two-day-old $A$. aegypti larvae (hatched from eggs supplied by the Danish Bilharziasis Laboratory, Charlottenlund, Denmark) were used. Distilled water $(2 \mathrm{ml})$ and $50 \mu \mathrm{l}$ bacterial suspension were dispensed in Nunc Multiwell 24 plates (Life Technologies, Denmark). A total of 40 larvae ( 5 per well) were used per bacterial strain. The larvae were kept at $28^{\circ} \mathrm{C}$, with a $14: 10$ (light:dark) photoperiod. Larval mortality was recorded 2 and 48 $\mathrm{h}$ post application.

The mortality caused by each strain was corrected for the control rate of mortality using Abbott's formula [18] by which the mortality observed in the control group (non-treated) is subtracted from the mortality observed in the treated groups.

\subsection{SDS-PAGE of $\delta$-endotoxin}

$\delta$-Endotoxin analysis was performed by sodium dodecyl sulfate-polyacrylamide gel electrophoresis
(SDS-PAGE) as described previously for characterization of $B$. thuringiensis using spore/crystal suspensions $[19,20]$. B. thuringiensis strains were cultured in T3 liquid sporulation media until sporulation was completed. Particulates from $100 \mu$ of sporulated culture were washed first with $1 \mathrm{M} \mathrm{NaCl}$ containing $5 \mathrm{mM}$ EDTA and then with $5 \mathrm{mM}$ EDTA. Washed crystals and spores were extracted $5 \mathrm{~min}$ at $100^{\circ} \mathrm{C}$ in $100 \mu 1$ sample buffer (50 mM Tris- $\mathrm{HCl}(\mathrm{pH} \mathrm{7.5),2 \%}$ (w/v) SDS, $0.05 \%(w / v)$ bromophenol blue, $1 \mathrm{mM}$ EDTA, 10\% (v/v) glycerol, $15 \mathrm{mM}$ DTT). Insoluble material was removed by centrifugation. Aliquots (15 $\mu \mathrm{l}$ each) were loaded onto $7.5 \%$ acrylamide gels (ExcelGel, Pharmacia Biotech, Denmark). Following electrophoresis, the gels were stained with $0.1 \%$ Coomassie blue R350 (PhastGel Blue R, Pharmacia Biotech). The molecular masses of proteins were determined with protein standards (low and high molecular weight standards, Pharmacia Biotech).

\subsection{Enterotoxin Vero cell assay}

The B. thuringiensis strains were cultured in brainheart infusion broth (Oxoid, UK), supplemented with $1 \%$ glucose, in an incubator with shaking (200 rev. $\left.\min ^{-1}\right)$ at $32^{\circ} \mathrm{C}$ for $6 \mathrm{~h}$. The cells were harvested by centrifugation $(5000 \times g$ for $20 \mathrm{~min})$ and the resulting supernatant was used in the cell assay and for electrophoresis/immunoblotting. The strains which did not show cytotoxicity with the supernatant fluid extract directly were concentrated 20 -fold with $70 \%$ 

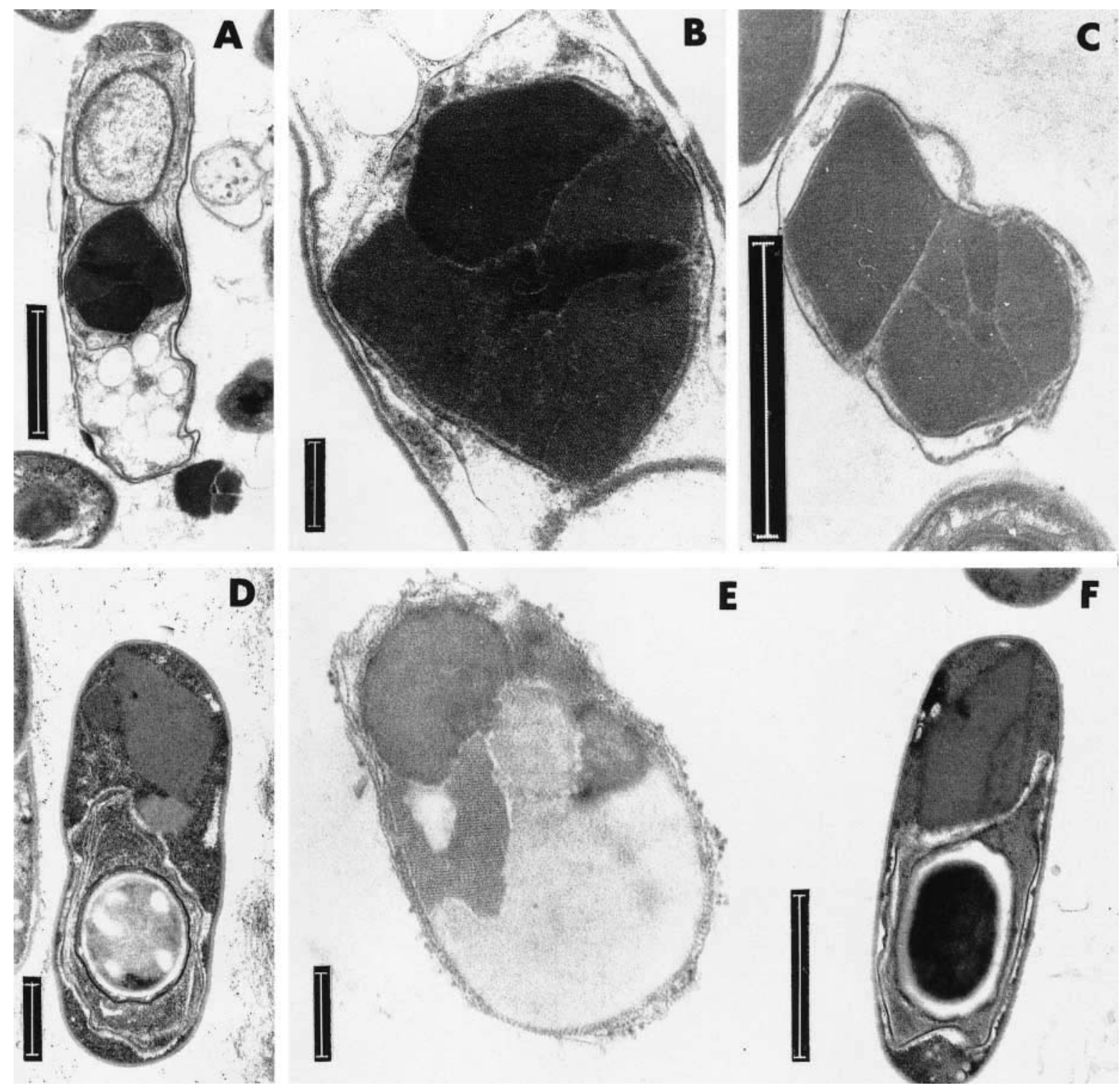

Fig. 1. TEM micrographs of parasporal inclusion bodies and spores of strains of Bacillus thuringiensis. (A) TBt- 85 isolated from a burn wound, developing spore and parasporal body during sporulation $(\mathrm{bar}=1 \mu \mathrm{m})$. (B) Magnification of parasporal body of TBt-85; note the inclusions of different electron densities (bar $=200 \mathrm{~nm})$. (C) TBt-82 isolated from burn wounds, close up of parasporal body $(\mathrm{bar}=1 \mu \mathrm{m})$. (D) Developing spore and parasporal body of B. thuringiensis serovar kurstaki (HD-1) just prior to lysis of the sporangium (bar $=500$ $\mathrm{nm}$ ). (E) Magnification of parasporal body of B. thuringiensis serovar israelensis (HD-567) (bar $=200 \mathrm{~nm}$ ). F, Developing cell of B. thuringiensis serovar morrisoni $(\mathrm{NB}-125)$ containing spore and parasporal body $(\mathrm{bar}=1 \mu \mathrm{m})$

ammonium sulfate precipitation. The precipitated protein was dissolved in $20 \mathrm{mM}$ phosphate buffer (pH 6.8) and dialysed against the same buffer for $16 \mathrm{~h}$ at $4^{\circ} \mathrm{C}$.

Cytotoxicity was determined by African green monkey kidney (Vero) cell assay according to Sandvig and Olsnes [21]. After $2 \mathrm{~h}$ incubation of the toxin extract with leucine-starved Vero cells, the reduced ability to incorporate $\left[{ }^{1} \mathrm{C}\right]$ leucine by the Vero cells was measured. All experiments were performed in 


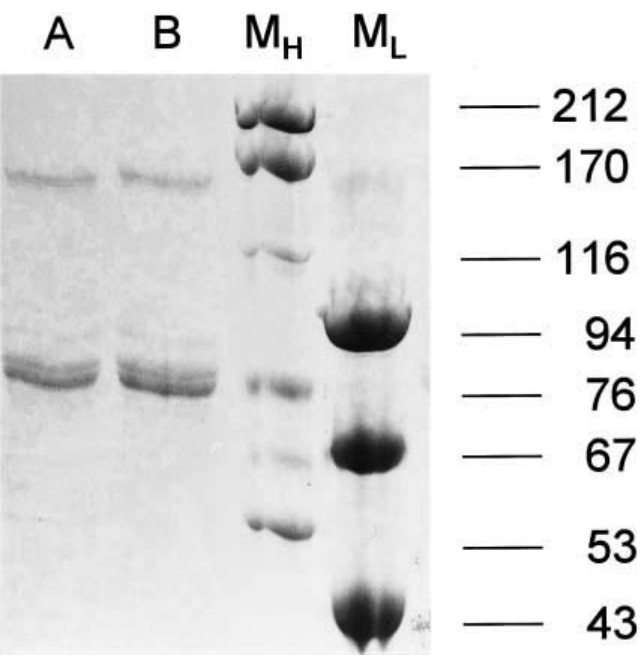

Fig. 2. Sodium dodecyl sulphate-polyacrylamide gel electrophoresis of Bacillus thuringiensis crystal proteins. Lane A, B. thuringiensis TBt-85; Lane $\mathrm{B}$, B. thuringiensis TBt-83; Lane $\mathrm{M}_{\mathrm{H}}$, High molecular weight marker; Lane $\mathrm{M}_{\mathrm{L}}$, Low molecular weight marker. Protein sizes are given in kilodaltons.

duplicate and were repeated twice. Cell extracts (concentrated 20 -fold) that gave at least $40 \%$ inhibition of protein synthesis in Vero cells were recorded as cytotoxic.

\subsection{Electrophoresis and immunoblotting of enterotoxin}

SDS-PAGE and Western immunoblots were carried out according to Towbin et al. [22] in a MiniProtean II Dual Slab Cell (Bio-Rad, USA). Antiserum against the purified enterotoxin was provided by John M. Kramer (PHLS Food Hygiene Laboratory, London, UK), prepared as previously described [23].

\section{Results}

Large square parasporal inclusion bodies were seen in all four isolated strains when viewed in both light and electron-microscope (Fig. 1A-C). It is seen that the inclusion bodies are composed of several components of different electron densities (Fig. 1B-C), which is also clearly noted from the inclusion body of $B$. thuringiensis serovar israelensis. The inclusions produced by the four strains isolated are of approximately the same size as the inclusions produced by the commercially available $B$. thuringiensis strains (Fig. 1D-F). The strains of B. thuringiensis serovar kurstaki and morrisoni produce rhomboidal forms (Fig. 1D,E), the strain of $B$. thuringiensis serovar israelensis produce roundish inclusions (Fig. 1C).

In the bioassays, none of the four strains showed any activity against either $P$. brassicae or $A$. aegypti in contrast to the commercially used strains $B$. thuringiensis serovar kurstaki $\mathrm{HD}-1$ and serovar israelensis HD-567 which are active against Lepidopteran and/or Dipteran insects (Table 1).

$\mathrm{H}$-serotyping of the strains from skin lesion and water samples showed none of them to move after inoculation in Craigie tubes and were non-flagellated.

The SDS-PAGE experiments revealed that the $\delta$ endotoxin was composed of three protoxins (Fig. 2), the sizes of which are 141,83 , and $81 \mathrm{kDa}$. Similar sizes of protoxins have not been reported previously.

Measurement of the cytotoxic effects on Vero cells was used as an indicator of the enterotoxic activity of the examined strains. In the assays, none of the four strains showed any toxicity to the Vero cells (Table 1). Furthermore, Western immunoblots showed that the strains did not produce enterotoxins.

\section{Discussion}

From the TEM analysis it is clearly evident that strains isolated by Valentino and Torregrossa [14] from burn wounds and water samples do not belong to $B$. cereus. All the isolated strains produced large parasporal inclusion bodies in the sporulating cells and, according to Bergey's Manual of Systematic Bacteriology [8], should consequently be classified as $B$. thuringiensis.

Expression of parasporal inclusion bodies composed of several inclusions as found for the isolated strains have previously been documented for strains of B. thuringiensis serovar israelensis. For strains of serovar israelensis the inclusions are composed on three different inclusions bound together by a laminated netlike envelope of undetermined composition [24]. 
This is the first report of the involvement of $B$. thuringiensis in non-gastrointestinal infections, apart from two cases of occupational health diseases: one needle-stick hand injury [25] and one case of corneal ulcers due to $B$. thuringiensis-based pesticides splashed into the eye [26]. Both accidents occurred during the handling of fluids containing highly concentrated $B$. thuringiensis spores and $\delta$-endotoxins.

From the data, it was clear that the strains isolated from the skin lesion and from the water samples were the same, which showed that the pathogen isolated from the skin infections originated from the water used in the treatment. Upon arrival at the Burns Centre of Palermo, patients are immediately immersed in a bath of warm water [14]. The same $B$. thuringiensis strains were isolated from both unchlorinated water and the hot-water tank serving the ward [14]. The routes of contamination of the water supplies are not known and could be numerous; however, it is completely clear that the contaminating bacteria do not originate from pesticide residues. The observed molecular size of the protoxins comprising the $\delta$-endotoxin are completely different from those used in commercial preparations and no non-flagellated $B$. thuringiensis strains are used commercially.

From a clinical point of view, in terms of treatment of non-gastrointestinal infections caused by $B$. cereus or B. thuringiensis, it is not important to know which of the two species is causing the infection, as the treatment is the same. But differentiation between the two species is of course important for monitoring the possible side-effects of using $B$. thuringiensis as a pesticide. As only a very limited number of ' $B$. cereus' strains from one location have been screened for the presence of parasporal inclusion bodies in this study, it is possible that more infections of both non-gastrointestinal and gastrointestinal character could have been diagnosed as $B$. cereus sensu lato, which includes $B$. thuringiensis. The method for identifying B. cereus, in both clinical and food hygiene microbiology, is the use of B. cereus-selective medium from which colonies are spread onto blood agar. B. cereus strains are identified by their irregular-edged colonies on blood agar and by the production of lecithinase and by the inability to ferment mannitol on selective media [27-29]. However, this method is completely unable to differentiate $B$. thu- ringiensis from $B$. cereus; the two species can only be differentiated by microscopic inspection after sporulation [8].

For the last 50 years $B$. thuringiensis have been used for insect pest control with no effects on the environment. Nevertheless, recently an incidence of food poisoning of hospitalized patients caused by a naturally occurring $B$. thuringiensis strain has been reported [30] and now also non-gastrointestinal clinical infections. However, it has to be stressed under which circumstances the infections described in this paper occurred. Patients with deep burn wounds on $30-70 \%$ of their body surface area are to be considered as highly immunosuppressed and thereby highly susceptible to infectious diseases including $B$. cereus sensu lato. However, B. thuringiensis strains tested for dermal infectivity under normal conditions, as a part of their registration for commercial use, have all been tested negative in such assays [31,32], and do therefore not constitute any human health hazards when used as a microbial pesticide [33].

\section{Acknowledgments}

The work by P.H. Damgaard was supported by the Danish Environmental Protection Agency (File No. M127-0563). We gratefully acknowledge the receipt of flagella antisera from Dr. M.M. Lecadet, Pasteur Institute, France, $P$. brassicae eggs from Dr. P. Jarrett, HRI, Wellsbourne, UK and $A$. aegyp$t i$ eggs from L. Petersen, DBL, Charlottenlund, Denmark. We also gratefully acknowledge the skilful technical assistance by Ilse Duun.

\section{References}

[1] Attwood, A.I. and Evans, D.M. (1983) Bacillus cereus infections in burns. Burns 9, 355-357.

[2] Dryden, M.S. (1987) Pathogenic role of Bacillus cereus in wound infections in the tropics. J. R. Soc. Med. 80, 480-481.

[3] Dryden, M.S. and Kramer, J.M. (1987) Toxigenic Bacillus cereus as a cause of wound infections in the tropics. J. Infect. 15, 207-212.

[4] Barrie, D., Wilson, J.A., Hoffman, P.N. and Kramer, J.M. (1992) Bacillus cereus meningitis in two neurosurgical patients - an investigation into the source of the organism. J. Infect. 25, 291-297.

[5] Alfaro, D.V., Roth, D.B., Laughlin, R.M., Goyal, M. and 
Liggett, P.E. (1995) Paediatric post-traumatic endophthalmitis. Br. J. Ophthalmol. 79, 888-891.

[6] Turnbull, P.C.B., Jørgensen, K., Kramer, J.M., Gilbert, R.J. and Parry, J.M. (1979) Severe clinical conditions associated with Bacillus cereus and the apparent involvement of exotoxins. J. Clin. Pathol. 32, 289-293.

[7] Morris-Coole, C. (1995) Bacillus thuringiensis: Ecology, the significance of natural genetic modification, and regulation. World J. Microbiol. Biotech. 11, 471-477.

[8] Claus, D. and Berkeley, R.C.W. (1986) Genus Bacillus Cohn $1872,174^{\mathrm{AL}}$. In: Bergey's Manual of systematic Bacteriology. (Sneath, P.H.A., Mair, N.S., Sharpe, M.E., Holt, J.G., Ed.), pp. 1105-1207. Williams and Wilkins, Baltimore, MD.

[9] Gordon, R.E. (1977) Some taxonomic observations on the genus Bacillus. In: Biological Regulations of Vectors: The Saprophytic and Aerobic Bacteria and Fungi. (Briggs, J.B., Ed.), pp. 67-82. US Dept. of Health, Education and Welfare, Publ. NIH 77-1180, Washington, DC.

[10] Priest, F.G., Goodfellow, M. and Todd, C. (1988) A numerical classification of the genus Bacillus. J. Gen. Microbiol. 134, 1847-1882.

[11] Carlson, C.R., Caugant, D.A. and Kolstö, A.B. (1994) Genotypic diversity among Bacillus cereus and Bacillus thuringiensis strains. Appl. Environ. Microbiol. 60, 1719-1725.

[12] Drobniewski, F.A. (1993) Bacillus cereus and related species. Clin. Microbiol. Rev. 6, 324-338.

[13] Ray, D.E. (1991) Pesticides derived from plants and other organisms. In: Handbook of Pesticide Toxicology. (Hayes, W.J., Laws, E.R., Ed.), pp. 585-639. Academic Press, San Diego, CA.

[14] Valentino, L. and Torregrossa, M.V. (1995) Risk of Bacillus cereus and Pseudomonas aeruginosa nosocomial infections in a burns centre: The microbiological monitoring of water supplies for a preventive strategy. Wat. Sci. Tech. 31, 37-40.

[15] Travers, R.S., Martin, A.W.P. and Reichelderfer, C.F. (1987) Selective process for efficient isolation of soil Bacillus spp. Appl. Environ. Microbiol. 53, 1263-1266.

[16] de Barjac, H. (1981) Identification of H-serotypes of Bacillus thuringiensis. In: Microbial Control of Pests and Plant Diseases (1970-1980). (Burges, H.D., Ed.), pp. 35-43. Academic Press, London.

[17] Damgaard, P.H., Larsen, H.D., Hansen, B.M., Bresciani, J. and Jørgensen, K. (1996) Enterotoxin producing strains of Bacillus thuringiensis isolated from food. Lett. Appl. Microbiol. 23, 146-150.

[18] Abbott, W.S. (1925) A. method of computing the effectiveness of an insecticide. J. Econ. Entomol. 18, 265-267.

[19] Chilcott, C.N. and Wigley, P.J. (1993) Isolation and toxicity of Bacillus thuringiensis from soil and insect habitats in New Zealand. J. Invert. Pathol. 61, 244-247.
[20] Smith, R.A. and Couche, G.A. (1991) The phylloplane as a source of Bacillus thuringiensis variants. Appl. Environ. Microbiol. 57, 311-315.

[21] Sandvig, K. and Olsnes, S. (1982) Entry of the toxic proteins abrin, modeccin, ricin and diphtheria toxin into cells. J. Biol. Chem. 257, 7495-7503.

[22] Towbin, H., Staehlin, T. and Gordon, J. (1979) Electrophoretic transfer of proteins from polyacrylamide gels to nitrocellulose sheets. Proc. Natl. Acad. Sci. USA 72, 4350-4354.

[23] Granum, P.E., Brynestad, S. and Kramer, J.M. (1993) Analysis of enterotoxin production by Bacillus cereus from dairy products, food poisoning incidents and non-gastrointestinal infections. Inter. J. Food Microbiol. 17, 269-279.

[24] Federici, B.A., Luthy, P. and Ibarra, J.E. (1990) Parasporal body of Bacillus thuringiensis israelensis. Structure, protein composition, and toxicity. In: Bacterial Control of Mosquitoes and Blackflies (de Barjac, H., Sutherland, D.J., Eds.), pp. 16 44. Rutgers University Press, New Brunswick, NJ.

[25] Warren, R.E., Rubenstein, D., Ellar, D.J., Kramer, J.M. and Gilbert, R.J. (1984) Bacillus thuringiensis var. israelensis protoxin activation and safety. Lancet i, 678-679.

[26] Samples, J.R. and Buettner, H. (1983) Corneal ulcer caused by a biologic insecticide (Bacillus thuringiensis). Am. J. Ophthalmol. 95, 258-260.

[27] Barrie, D., Hoffman, P.N., Wilson, J.A. and Kramer, J.M. (1994) Contamination of hospital linen by Bacillus cereus. Epidemiol. Infect. 113, 297-306.

[28] Anonymous. (1993) Bacillus cereus. Determination in foods. Nordic Committee on Food Analysis 67 (3 ed.), Statens Tekniska Forskningscentra, Esbo.

[29] Anonymous. (1993) Microbiology - General Guidance for the Enumeration of Bacillus cereus - Colony-count Technique at $30^{\circ} \mathrm{C}$. International Standard 7932 (2nd ed.) International Organization for Standardization, Genève.

[30] Jackson, S.G., Goodbrand, R.B., Ahmed, R. and Kasatiya, S. (1995) Bacillus cereus and Bacillus thuringiensis isolated in a gastroenteritis outbreak investigation. Lett. Appl. Microbiol. 21, 103-105.

[31] Siegel, J.P. and Shadduck, J.A. (1990) Mammalian safety of Bacillus thuringiensis israelensis. In: Bacterial Control of Mosquitoes and Black Flies: Biochemistry, Genetics and Applications of Bacillus thuringiensis israelensis and Bacillus sphaericus (de Barjac, H., Ed.), pp. 202-217. ASM, New Jersey.

[32] McClintock, J.T., Schaffer, C.R. and Sjoblad, R.D. (1995) A comparative review of the mammalian toxicity of Bacillus thuringiensis-based pesticides. Pesticide Sci. 45, 95-105.

[33] Drobniewski, F.A. (1994) The safety of Bacillus species as insect vector control agents. J. Appl. Bacteriol. 76, 101-109. 